\section{Case Reports in Neurology}

Case Rep Neurol 2020;12:176-177

DOI: 10.1159/000509506

Published online: December 14, 2020
(C) 2020 The Author(s)

Published by S. Karger AG, Basel www.karger.com/crn

This article is licensed under the Creative Commons Attribution-NonCommercial 4.0 International License (CC BY-NC) (http://www.karger.com/Services/OpenAccessLicense). Usage and distribution for commercial purposes requires written permission.

\title{
Uncommon Causes of Cardioembolic Stroke and Related Complications
}

\author{
Nilanont Yongchai ${ }^{a} \quad$ Narayanaswamy Venketasubramanian $^{\mathrm{b}}$ \\ Kay $\operatorname{Sin} \operatorname{Tan}^{c}$ \\ aDepartment of Medicine, Siriraj Hospital, Mahidol University, Bangkok, Thailand; ${ }^{b}$ Raffles \\ Neuroscience Centre, Raffles Hospital, Singapore, Singapore; 'Division of Neurology, \\ Department of Medicine, University of Malaya, Kuala Lumpur, Malaysia
}

Embolism of cardiac origin accounts for approximately one fifth of all ischemic strokes. Nonvalvular atrial fibrillation is by far the most extensively studied. Other causes of "high risk cardioembolic stroke" such as infective endocarditis, left atrial myxoma, dilated cardiomyopathy, left ventricular thrombus, sick sinus syndrome, mechanical prosthetic valve, and mitral stenosis with atrial fibrillation are well recognized causes of cardioembolic stroke. In this supplementary issue of Case Reports in Neurology, 3 unusual cardioembolic stroke cases were expounded: a young-onset stroke patient with left ventricular thrombus associated with doxorubicin-induced cardiomyopathy [1], a case of nonbacterial thrombotic endocarditis related to adenocarcinoma of uterine cervix which is a rare condition and usually diagnosed in the past by autopsy [2], and lastly, a case with multiple cerebral aneurysms detected a decade later after resection of cardiac myxoma [3]. The authors have described these case scenarios with appropriate illustrations as well as imaging studies which highlighted lessons learned from each case.

\section{Disclosure Statement}

The authors have no conflicts of interest to declare

\section{Funding Sources}

This journal supplement was funded by an unrestricted educational grant from Moleac Pte. Ltd.

\begin{tabular}{ll}
\hline & Kay Sin Tan \\
Division of Neurology, Department of Medicine & University of Malaya, Pantai Valley \\
Kuala Lumpur 50603 (Malaysia) \\
tanks18@hotmail.com; tanks_neuro@um.edu.my
\end{tabular}




\section{Case Reports in Neurology}

\section{Author Contributions}

N.Y. completed the first draft of the paper and approved the final manuscript.

N.V. and K.S.T. reviewed the paper for content, provided critical feedback, and approved the final manuscript.

\section{References}

1 Lee E-J, Yoon B-W. Acute ischemic stroke in young patient with left ventricular thrombus attributed to doxorubicin cardiomyopathy. Case Rep Neurol. 2019;4:5.

2 Kijpaisalratana N, Chutinet A, Travanichakul S, Kitjawijit T, Yokumporn P, Duangjino K, Suwanwela NC. Nonbacterial thrombotic endocarditis related to adenocarcinoma of uterine cervix. Case Rep Neurol. Case Rep Neurol. 2019;6:3

3 Jain S, Nga VDW, Venketasubramanian N. Late diagnosis of multiple cerebral aneurysms a decade after resection of cardiac myxoma. Case Rep Neurol. 2019;10:15. 